\title{
CHLOROFLUOROCARBON LEAK DETECTION TECHNOLOGY
}

\author{
E. B. Munday \\ Process Technology Department \\ Technical Division
}

Date Published - December 1990

\author{
Prepared by the \\ Uranium Enrichment Organization \\ Oak Ridge, Tennessee 37831 \\ managed by \\ MARTIN MARIETTA ENERGY SYSTEMS, INC. \\ for the \\ U.S. DEPARTMENT OF ENERGY \\ under contract No. DE-AC05-84OR21400
}




\section{CONTENTS}

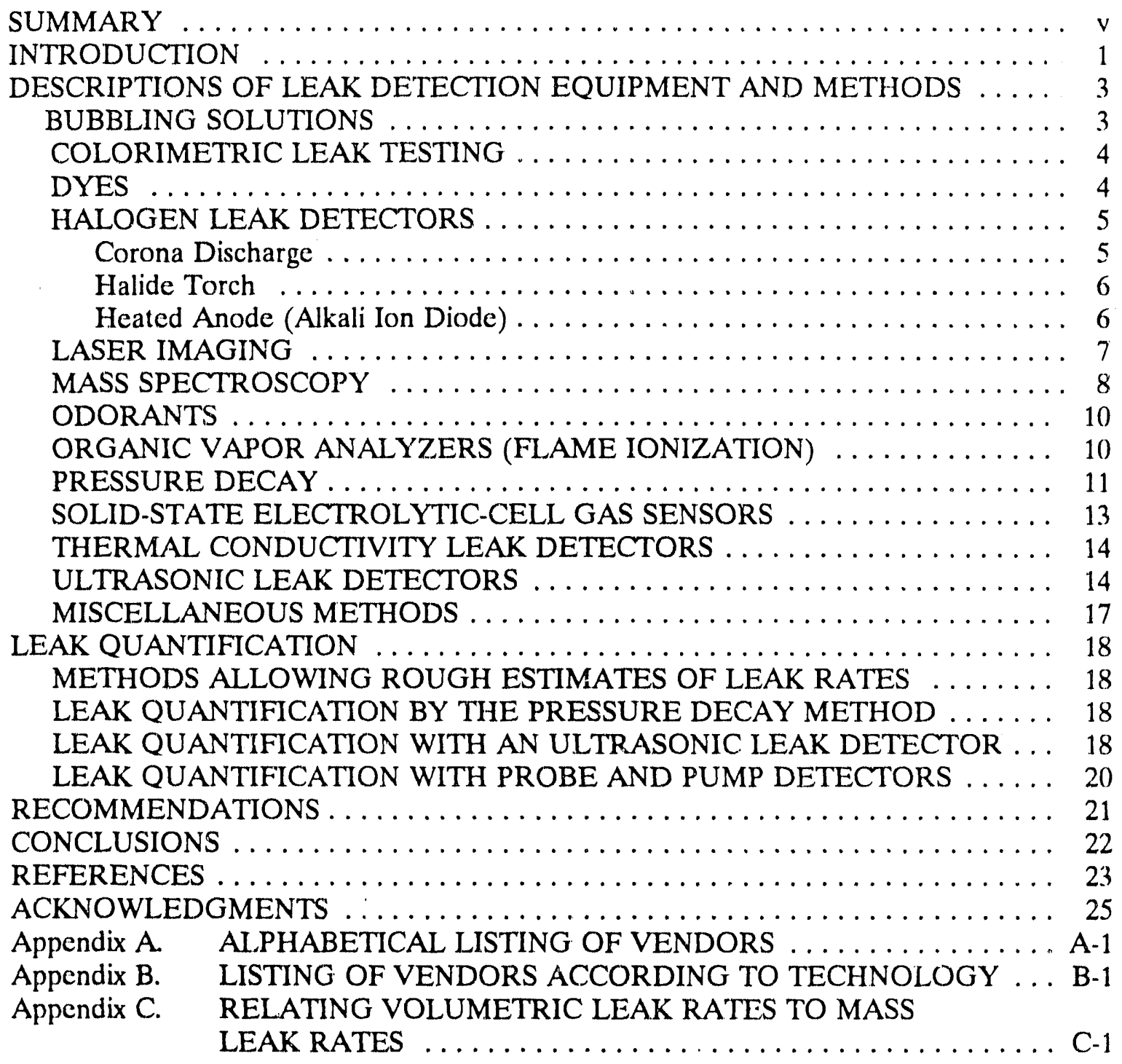




\section{SUMMARY}

There are about 590 large coolant systems located at the Portsmouth Gaseous Diffusion Plant (PORTS) and the Paducah Gaseous Diffusion Plant (PGDP) leaking nearly 800,000 lb of R-114 refrigerant annually (1989 estimate). A program is now under way to reduce the leakage to $325,000 \mathrm{lb} /$ year-an average loss of $551 \mathrm{lb} /$ year $(0.063 \mathrm{lb} / \mathrm{h})$ per coolant system, some of which are as large as $800 \mathrm{ft}^{3}$.

This report investigates leak detection technologies that can be used to locate leaks in the coolant systems. Included are descriptions, minimum leak detection rate levels, advantages, disadvantages, and vendor information on the following technologies: bubbling solutions; colorimetric leak testing; dyes; halogen leak detectors (coronea discharge detectors; halide torch detectors, and heated anode detectors); laser imaging; mass spectroscopy; organic vapor analyzers; odorants; pressure decay methods; solid-state electrolytic-cell gas sensors; thermal conductivity leak detectors; and ultrasonic leak detectors.

The TIF 5000 halogen leak detectors (corona discharge type) and bubbling solutions that presently are used at PGDP and PORTS are capable of detecting leaks as small as 0.03 $\mathrm{lb} /$ year. This level of sensitivity seems far more than adequate, since a coolant system with 18,000 leak sites each leaking $0.03 \mathrm{lb} /$ year would leak only $540 \mathrm{lb} /$ year. More sensitive instruments would not necessarily improve leak detection capability; in fact, detection capability would be hindered since the more sensitive instruments are also more difficult to use.

Surprisingly few leaks are found with the presently used methods. One explanation is that most leakage occurs at a few large leak sites. The ultrasonic leak detector is ideal for surveying large leaks since it can be used more rapidly than other detectors and can be used to estimate leakage rates.

Calibrated leak sources of different sizes should be obtained to experimentally confirm leak rate sensitivity and to investigate leak rate size determination using different instruments. The organic vapor analyzer is perhaps the most promising instrument for use in measuring leakage rate as it is a battery-powered, sensitive instrument equipped with a sample pump and designed to give a concentration readout in parts per million.

The pressure decay method may allow estimation of the overall coolant system leakage rate if temperature effects are not excessive. The use of dye, odorant, or colorimetric methods would require the addition of chemical agents to the coolant system. The dye approach seems more attractive than the other two methods, but evaluation of possible short- and long-term effects on the refrigerant and coolant system components would be necessary before dyes could be added to the system. Also, the consequences of leakage to the process gas would require evaluation prior to dye method implementation. 


\section{INTRODUCTION}

Martin Marietta Energy Systems, Inc. (Energy Systems), is the operating contractor for the Department of Energy (DOE)-owned gaseous diffusion plants, PORTS and PGDP, located at Portsmouth, Ohio, and Paducah, Kentucky, respectively. These plants use chlorofluorocarbon refrigerant $(\mathrm{R}-114)$ in coolant systems to remove the heat of compression from uranium hexafluoride $\left(\mathrm{UF}_{6}\right)$ gas after large compressors have forced the gas through the diffusion barrier as part of the uranium enrichment process.

Several types of gaseous diffusion equipment are presently used at each plant site, and the size and number of the coolant systems vary in different process buildings according to equipment type. However, all coolant systems consist of more than one tube-and-fin counterflow evaporator connected to one water-cooled shell-and-tube condenser. The evaporators contain liquid R-114 and are located on a lower floor in relation to the condenser. Heat transfers from the hot $\mathrm{UF}_{6}$ gas through the evaporator walls and causes the liquid R-114 to boil. The vapors rise to the water-cooled condenser resulting in the condensation of the R-114, which gravity causes to flow back down to the evaporator. Pumps or compressors are not required for circulation of the R-114 while the systems are in operation, although such equipment is required to evacuate liquid and vapor R-114 prior to maintenance. The water heated as a result of the process is pumped to a cooling tower, and, consequently, the heat originally transferred from the hot $\mathrm{UF}_{6}$ is released to the outside environment primarily in the form of energy of evaporation of the cooling tower water.

The evaporators and condenser of each cooling system are connected by pipe of varying sizes. The cooling system also includes sight glasses, sample lines, evacuation lines, pressure relief devices, and valves at various locations. The volume of the largest cooling systems (associated with 000 converter equipment) is approximately $800 \mathrm{ft}^{3}$ with a R-114 inventory of $25,000-50,000 \mathrm{lb}$. The operating temperature and pressure are roughly $160^{\circ} \mathrm{F}$ and 110 psia.

Ideally, the cooling systems allow a closed loop process with no consumption of R-114 coolant, but in practice there are over 590 cooling systems at PORTS and PGDP combined that contain an inventory of approximately 14.7 million $\mathrm{lb}$ leaking approximately $800,000 \mathrm{lb}$ of R-114 annually (1989 estimate). The leakage is due to the high pressure and numerous leak sites present in the cooling systems. It is also related to the vibration levels of operating gaseous diffusion equipment (especially the 000 equipment), which tend to cause new leak sites to occur. Apparently the large majority of leakage occurs from the coolant systems to ambient air within the process building with only sight leakage to the cooling water or the process gas.

A goal has been set to reduce the present leakage rate from $800,000 \mathrm{lb} /$ year to $325,000 \mathrm{lb} / y e a r$ by 1994 , and an important part of that goal is to improve the present methods of leak detection if possible. Currently leaks are located by surveying operating cooling systems with bubbling solutions and small hand-held halogen leak detectors (TIF 5000 by TIF Instruments, Inc.). At PORTS the cooling systems out of service for maintenance receive a 
1 -h pressure decay test at $100 \mathrm{psig}$ initial air pressure prior to restart, but this method is known to be insensitive except to very large leaks.

This report documents an extensive vendor review and literature survey to identify available equipment and methods that may improve leak detection capabilities. The product's ability to quantity leaks is also an important objective since quantification would help establish priorities for maintenance activities, thereby, conserving resources. The vendor review consisted of examining the appropriate listings in the Thomas Register and Visual Search Microfilm File (VSMF). The preliminary review of over 350 vendors narrowed the list to about 50. Lists of vendors in alphabetical order and by equipment type are contained in Appendix A and B, respectively. The literature survey consisted of keyword searches of computer data bases, separate reviews of technical societies likely to have an interest in leak detection (such as the American Society for Testing and Materials), and a search of the Oak Ridge K-25 Site library microfilm report index for articles that may have been written at that site. 


\section{DESCRIPTIONS OF LEAK DETECTION EQUIPMENT AND METHODS}

\section{BUBBLING SOLUTIONS}

The use of bubbling solutions to detect small gas leaks under pressure is one of the simplest, least expensive, and oldest methods available. It is also an effective method, which is reportedly capable of detecting leaks as small as $10^{-4} \mathrm{std} \mathrm{cc} / \mathrm{s}$ for low viscosity, low molecular weight gases. The sensitivity improves approximately with the difference in the squares of the pressures within and without the test vessel, and inversely to the viscosity of the leaking gas and to the surface tension of the bubbling solution. A bubbling solution with low surface tension helps promote surface wetting, and smaller, more numerous bubbles are formed.

Commercially available leak test solutions are usually more desirable than soap solutions for the following reasons: (1) soap is usually alkaline with a $\mathrm{pH}$ of 10.5 to 11.5 , which can cause corrosion of metal; (2) soap will accumulate on surfaces over a period of time and leave a sticky film; (3) soap usually contains salts that can leave conductive films, which can eventually increase shock hazards near electrical equipment; (4) soap may contain chlorides and borax, which can cause stress-corrosion cracking in stainless steel or titanium; (5) commercial solutions can be specially formulated for use with a specific gas for a specific temperature range and they can be prepared with a balanced surface tension - low enough to promote good wetting, yet high enough to keep bubbles from breaking too soon; (6) commercial solutions overcome most of the disadvantages of soap solutions; they are usually formulated to a $\mathrm{pH}$ of 6 to 8 and leave much less residue upon evaporation; and (7) commercial solutions maintain their properties over long storage periods and are not subject to bacterial action. ${ }^{1,2}$

Specially formulated bubbling solutions are available that are more sensitive and generally more desirable to use than standard soap solutions for the reasons listed above. Some commercial solutions are formulated to create a white foam that becomes visible ten seconds to several minutes after exposure to smail leaks. Sherlock Leak Detection Fluid manufactured by Winton Products Co., Inc., is an example of such a fluid intended for use over a temperature range of 35 to $160^{\circ} \mathrm{F}$. A commercial solution similar to Sherlock was evaluated on leaks of R-12 by the American Society for Nondestructive Testing (ASNT) and the American Society for Metals (ASM). The results indicated that leaks as small as $0.01 \mathrm{lb} /$ year were detectable. (The particular solution used and the test pressure were not revealed.) ${ }^{1}$

When using bubbling solution, several considerations should be noted: (1) the solution may be flowed or sprayed, but should not be brushed onto the test surface as brushing will result in many bubbles that will obscure any leakage indication; (2) a large leak may blow liquid clear without bubbles; (3) when testing flanges, threads, joints, etc., the film must be capable of bridging the joint; (4) a magnifying glass of 2 to 3 power and a flashight are often helpful for identifying leaks; (5) if a more sensitive leak test is to be used following a bubble test, remember that the bubbling solution should be cleaned from the surface or small leaks may be blocked temporarily by the solution. ${ }^{1,2}$ 
Although commercial solutions are usually preferable to soap solutions, soap solutions may prove convenient and acceptable for noncritical applications. A shop-mixed formula of one part liquid detergent to one part glycerine to $41 / 2$ parts water is suggested by the ASNT. The solution should be mixed far enough in advance of use to allow bubbles to disperse, but should not be used after lengthy storage. ${ }^{1}$

\section{COLORIMETRIC LEAK TESTING}

Colorimetric leak testing generally employs two chemical agents - a tracer (which is a gas) and a developer (which is applied to the outside surface of the test vessel). The method usually employs anhydrous ammonia or an ammonia-nitrogen mixture (1-100\% ammonia by volume) as a tracer at a pressure that may range from 5 to $100 \mathrm{psig}$. The developer is usually a water-based chemical sprayed on the outside of the test vessel and allowed to dry prior to pressurization of the vessel with the tracer gas. The tracer gas leaks through passages in the vessel and reacts chemically with the developer resulting in an easily observable color change. ${ }^{3}$ The active chemical agent in the developer is often bromocresol dye, which changes to a vivid purple upon reaction with ammonia gas. The method is highly effective with a sensitivity of $1 \times 10^{-7} \mathrm{std} \mathrm{cc} / \mathrm{s}\left(5.3 \times 10^{-5} \mathrm{lb} / \mathrm{yc}\right.$ car $\left.\mathrm{R}-114^{\circ}\right) .^{3}$ The method is often used on large pressurized vessels such as are found on liquefied natural gas transport ships.

For maximum effectiveness, the test surface should be carefully cleaned of oil, grease, or anything else that might mask leakage. A new unpainted vessel should be leak tested prior to painting. Impregnated filter paper may be used to cover areas that are not easily sprayed, such as gaps between flanges and valves. Three successive increases and decreases in pressure during the test may be more successful in revealing small, intermittent leaks than overpressurization. The pressurization is performed in stages beginning at low pressure to observe larger leaks and to allow their repair prior to proceeding to higher pressures. ${ }^{3}$

Although the colorimetric method is highly effective, there are obvious disadvantages. Ammonia is a potentially hazardous gas that poses explosive as well as toxic dangers. Workers should wear ammonia-sensitive badges to indicate exposure levels. The developer must be removed from the test surfaces following the evaluation. Ammonia gas will attack copper or brass if moisture is present, and the ammonia must be purged from the vessel and disposed of after the testing. (This is usually done by dissolving the ammonia gas in water.) ${ }^{3}$

\section{DYES}

The use of penetrant dyes for leak testing has several variaiiưns: (1) : 'iquid colored dye is mixed with the liquid normally contained in the test vessel, so the dye may be observed if the liquid leaks through passages in the vessel wall; (2) a liquid dye is employed as in the previous example, but the dye is fluorescent and leak sites are revealed by ultraviolet light; (3) a liquid chemical agent (not necessarily a dye) is mixed with the liquid normally contained in the test vessel, and a developer is sprayed on the outside surface of the test vessel so that if a leak is present, the chemical passing through the wall will react with the developer

\footnotetext{
'See Appendix C for calculations relating std cc/s to lb/year of R-114.
} 
changing its color in a manner similar to the gaseous colorimetric method. ${ }^{4}$ In most cases, the use of dyes is applicable only to the portion of the vessel in the liquid phase, but Spectronics Corporation claims their fluorescent dye will volatilize with Freon ${ }^{\text {TM }}$ to allow leak detection in the vapor phase.

Penetrant dyes are difficult to clean and generally messy to use. Penetrants will often cause skin irritation during continual skin exposure because of the oil or solvent base usually employed. ${ }^{4}$ The vendor literature of the American Gas and Chemical Company states that the sensitivity with liquid penetrants is about the same as that possible with bubbling solutions. The American Society for Metals cautions that heating penetrant materials much above room temperature can increase the viscosity and destroy the fluorescence. ${ }^{4}$

\section{HALOGEN LEAK DETECTORS}

Halogen leak detectors are distinguished from other gas leak detectors by their dependence upon the chemically reactive nature of the halogens. Halogen leak detectors are especially applicable to detection of CFC leaks because of the chlorine and fluorine atoms bound in the coolant's molecules. When using a halogen leak detector, care must be taken to avoid contaminating the air with any compounds containing halogens (dry cleaning fluid vapors, degreaser vapors, cigarette smoke, etc.), since the detector does not distinguish halogens in Freon ${ }^{\mathrm{M}} \mathrm{M}$ from halogens in other sources. R-12 has historically been used as a tracer gas to pressurize test vessels to allow leak testing with nalogen leak detectors. R-12 and $\mathrm{R}-114$ reportedly will cause the same indication on a halogen leak detector at an equal volumetric leak rate. ${ }^{1}$

Four types of halogen leak detectors are identified in this study: (1) corona discharge, (2) halide torch, (3) heated anode (alkali ion diode), and (4) electron-capture. Each of these types will be described below except the electron-capture halogen leak detector, which is omitted because this type instruinent requires a tritium radioactive source and is reportedly no longer manufactured. ${ }^{1}$

Halogen leak detectors are similar to certain other classes of leak detectors in that they have a probe that must contact the gas. The vendor-quoted sensitivity of the instruments is usually arrived at under ideal laboratory conditions and based on the assumption that the probe is in direct contact with the leak. ASNT and ASM recommend a probe survey speed of $5 \mathrm{ft} / \mathrm{min}$, which makes surveying a large surface very time consuming, especially considering the small area of the probe. ${ }^{1}$

\section{Corona Discharge}

The corona discharge halogen leak detector employs a sensing tip with a high voltage gap that ionizes the air, forming an electrical corona discharge and allowing current to flow between the gap. The instrument's electronics translate the current into a slow, steady beeping sound, usually accompanied by a blinking diode light indicator. If halogens are present in the air between the gap, the halogens (due to their high electronegativity) will 
capture electrons from the ionized air, causing the current to decrease. The electronics respond inversely proportionally to the magnitude of the current, and an increased concentration of halogen causes an increased signal indication. ${ }^{5}$

The corona discharge halogen leak detectors are typically small, hand-held, inexpensive units, which find common application among refrigeration mechanics. They are capable of detecting leaks as low as $0.03 \mathrm{lb} /$ year. The TIF 5000, which is presently in use at PORTS and PGDP, is of this type.

\section{Halide Torch}

A halide torch halogen leak detector does not use electronic instrumentation, but rather a simple flame test. A small torch burns a halogen-free fuel with the flame impinging upon a copper plate. Part of the air required for combustion is drawn tinrough the test prote; if halogen is present, the flame color will change to green, characteristic of copper. (The chemically active halogen ionizes and reacts with a small amount of copper at the high flame temperature causing copper atoms to become airborne.)

The halide torch is inexpensive and gives a fast, reliable response, but the flame poses a hazard in some work environments. Also the fuel tank must be replaced, and observing a flame can irritate one's eyes. The instrument should not be used in confined areas since the flame consumes oxygen, emits combustion products, and may generate toxic gases by decomposing halogen compounds. The halide torch is capable of detecting leak rates of R-12 as low as 0.5 lb/year. ${ }^{1}$ The instrument is the least expensive halogen detector and may he preferred by persons wanting a detector for occasional use. Cooper Tools Division is one vendor for the instrument.

\section{Heated Anode (Alkali Ion Diode)}

The heated anode halogen leak detector uses a sensor that consists of an alkali ion emitter and an alkali ion collector. The emitter is a porous ceramic plug containing absorbed alkali metal (usually sodium, potassium, or lithium) and constitutes an anode. The collector is a cathode consisting of a platinum coil that surrounds the emitter, but is electrically insulated from it. A small coil heats the sensor to approximately $900^{\circ} \mathrm{C}$, causing positive alkali ions to migrate to the emitter surface where a small current of the ions will flow to the cathode. If a halogen bearing gas is present between the emitter and collector, the halogen will ionize due to the high temperature and cause an increase in the alkali ion flow between the anode and cathode proportional to the halogen concentration. An unusually sensitive reading is possible because each halogen ion allows the emission of numerous alkali ions; hence, the instrument is often called an alkali ion diode halogen leak detector. A suction pump draws the sample gas through the test probe to the sensor, and instruments are often microprocessor controlled with automatic regulation of sample flow rate, sensor temperature, and front panel readout. ${ }^{6}$

These instruments are capable of greater sensitivity than the corona discharge or halide torch instruments and allow a possible means of quantifying leaks. The ideal sensitivity of 
heated anode detectors is as low as $1 \times 10^{.7} \mathrm{std} \mathrm{cc} / \mathrm{s}\left(5.3 \times 10^{-5} \mathrm{lb} /\right.$ year R-114), but true sensitivity in a factory environment is closer to $1 \times 10^{-5} \mathrm{std} \mathrm{cc/s}{ }^{7}$ They have the following inherent limitations that must be understood and for which compensation must be planned.

- The sensitivity of the instrument slowly changes because the alkali source is slowly consumed. This is not necessarily a problem if the instrument is being used solely to locate leaks, but if leak quantification or leak detection to a definite specification is desired, a calibrated leak source should be used every two hours to check the level of sensitivity.

- The life of the emitter is more a function of the amount of halogen to which it is exposed rather than the length of time the insirument is used.

- An increase of halogen ion concentration beyond a certain point will not result in an increased flow of alkali ions because the transport of alkali to the emitter surface is the rate controlling step. In this case, the sensor will become saturated, but the instrument usually will recover after removal from the halogen source.

- The sensitivity of the instrument may drift with temperature. ${ }^{1}$

- All commercially available instruments of this type observed during the vendor survey required an electrical outlet for the power supply.

The American Society for Testing and Materials (ASTM) publishes standards for heated anode halogen leak cetectors, which also lists desired specifications for the instruments." ASNT and ASM describe the detectors and calibrated leak sources used to calibrate detectors manufactured by General Electric (GE). Additional details of their operation, limitations, and advantages are available in the ASNT-ASM volume. ${ }^{1}$

Sentech Corporation manufactures halogen leak monitors that use GE sensors as the basic detection instrument. Sentech offers both ambient-air and water monitoring units. The water monitor (called Water Spaniel) is intended to detect Freon ${ }^{T M}$ in chilled water. The Water Spaniel heats the cold water to $70^{\circ} \mathrm{F}$, driving the Freon ${ }^{\mathrm{TM}}$ from the water. The Freon ${ }^{\mathrm{TM}}$ is then detected by a GE halogen vapor sensor. This result suggests that Freon ${ }^{\mathrm{TM}}$ leaks to cooling tower water may not dissolve in the water, since the cooling tower water is much warmer than $70^{\circ} \mathrm{F}$.

\section{LASER IMAGING}

Electromagnetic radiation is characterized by wavelength. Visible light is a form of electromagnetic radiation corresponding to an interval of wavelengths that can be perceived by the human eye. Most electromagnetic radiation falls within broad intervals of wavelengths shorier than light (known as ultraviolent radiation) and wavelengths longer than light (know as infrared radiation). Each gas will absorb electromagnetic radiation of a particular wavelength; such absorption is an identifying characteristic of the particular gas. This characteristic allows for a possible means of detecting a particular gas in air. 
Most sources of electromagnetic radiation emit a broad band of wavelengths that spans the interval from ultraviolent to infrared. Lasers emit radiation with a very narrow interval and offer a technique for observing gas leakage otherwise invisible to the eye. A laser tuned to the known absorption frequency of the gas scans the area for a leak; objects in the area reflect (backscatter) some of the radiation to a sensor; an electronic instrument interprets the sensor signal to a video monitor; and, if gas leakage is occurring, the gas will absorb some of the radiation, consequently causing the gas plume to appear on the video monitor as a dark cloud. Two laser systems are presently available: Backscatter Absorption Gas Imaging (BAGI) and Differential Absorption Lidar (DIAL). Lidar stands for "light detection and ranging" and is similar in principle to radar, which stauds for "radio detection and ranging."

The BAGI system works essentially as described above and employs an infrared beam from a carbon dioxide laser. Laser Imaging Systems (LIS) presently manufactures a laser unit, which is shoulder carried and is about the size of a video camcorder. (A power cord is required.) R-114 is on the LIS data base of detectable gases, and the unit is reportedly capable of detecting leaks of $88 \mathrm{lb} / y e a r$ at standard temperature and pressure with an airspeed of $5 \mathrm{~cm} / \mathrm{s}$. The unit does not allow quantification of leaks. The BAGI init presently costs about $\$ 60,000$.

The DIAL system is similar to the BAGI system except that the DIAL systern emits two wavelengths of lase radiation simultaneously, with one of the wavelengths serving as a reference signal and the other corresponding to a selective absorption frequency for the leaking gas. Since both beams transverse the same air and reflect off the same objects, any difference in magnitude between the two reflected beams must be due to gas absorption and proportional to the amount of gas present. This system allows for a more quantitative determination of the leakage rate than is possible with the BAGI system. DIAL systems can be used at ranges of over 5 miles for large outdoor releases. They are often mounted on a trailer and are much larger and more expensive than BAGI units. ${ }^{8}$ Tecan Remote, Inc., manufactures the units.

Neither the DIAL nor the BAGI systems seems applicable presently to CFC coolant system leak detection problems because of the systems' poor sensitivity, bulky size, and high cost compared to other methods. Also, the layout of the cooling systems makes scanning with the instruments difficult. Since this technology is rapidly developing, great improvements may result regarding the efficiency, size, and cost of the units; therefore, the technology should be reevaluated every several years.

\section{MASS SPECTROSCOPY}

Mass spectroscopy is based on an application of the laws governing electrostatic and magnetic forces. The atoms of a gas are ionized by a beam of electrons in the ionization chamber and then propelled toward the mass spectrometer chamber by electrostatic force. Certain ions pass through small holes in several plates to form a narrow beam (other ions are

blocked by the plates). The ion beam soon moves beyond the influence of the electrostatic field that originally propelled it from the ionization chamber, and the ions are traveling at different velocities. 
The ion beam enters a region between two parallel electrostatically charged plates located within a uniform magnetic field. (The direction of the magnetic field is perpendicular to the ion velocity.) The plates are oriented so that the electrostatic force exerted by the plates can be made to counterbalance the magnetic force. However, since the magnetic force is a function of the velocity of the ions, only ions of the same velocity are balanced, reducing the ion beam to particies traveling at the same velocity. As the ions travel past the clectrostatic field, they are bent by the magnetic force to different degrees depending upon their masses. This bending allows separation and identification of different atoms.

In theory, a mass spectrometer could be used to detect R-114 molecules as they leak from a vessel, but helium and hydrogen ions are much easier to distinguish than other molecules due to their higher charge-to-mass ratios. Thus, helium is often used as a tracer gas; helium is used rather than hydrogen because helium is present in the atmosphere in much lower concentrations, so background contamination is iess. Mass spectrometers used for leak detection are therefore often called helium leak detectors. ${ }^{1}$

The sensing element of a mass spectrometer will be damaged if not operated at sufficient vacuum, the valve for which varies among manufacturers. The sensing element pressure for most instruments is about $10^{-4}$ torr, although they can operate above this level for a shorter lifetime. ${ }^{1}$ Vacuurn Instrument Corporation advertises that the MD-180 series of helium leak detectors can be operated with an inlet pressure as great as 7 torr. If a helium leak detector is used to detect outleakage from a pressurized vessel, the sample stream must be greatly throttled to maintain the sensor operating pressure, and the sample stream will be highly diluted in air. The helium leak detector is less sensitive than the heated anode halogen leak detector in this mode of operation; ${ }^{9}$ since the halogen leak detector is simpler to operate, smaller, less expensive, and can detect R-114 already in the vessel, there is no advantage using the helium detector.

The helium lcak detector may offer a possible advantage concerning leak detection sensitivity (as much as 10,000 times more sensitive than the heated anode halogen leak detector) if the sensor is installed in a line to the test vessel with the vessel at a vacuum near the operating pressure of the sensor. ${ }^{1}$ In this mode helium gas is sprayed along the vessel by an operator in radio commurication with a second operator at the helium leak detector. When helium is sprayed at a leak site, some gas will enter the leak and make its way to the detector. (A vacuum pump on the mass spectrometer pulls gases through the sensor.) The disadvantiges of this method are that the entire vessel would require evacuation to near the operating sensor pressure, which would be a time-consuming operation, and there would still be a sime lag between spraying the helium at the leak site and receiving an indication at the leak rietector.

The ASNT warns that vendors of helium leak detectors often advertise sensitivities in the range of $2 \times 10^{-10}$ to $1 \times 10^{-12} \mathrm{std} \mathrm{cc} / \mathrm{s}$, but that these figures pertain to ideal laboratory conditions that cannot be approached in practice since the electronic noise inherent in the instruments usually exceeds the claimed sensitivity. ${ }^{1}$ The ASTM publishes a standard for using a mass spectrometer for leak detection in the tracer probe mode (vessel at a vacuum) ${ }^{10}$ and a separate standard for leak detection in the detector probe mode (vessel under pressure) ${ }_{11}^{11}$ both of which contain additional details concerning this system. 


\section{ODORANTS}

The addition of an odorous agent to an otherwise odorless gas to allow for deturmination of gas leakage is a detection system commonly employed in the natural gas industry. The same concept could be applied to the cascade coolant systems. Saccavino and Vanek have obtained a patent that specifically applies to the addition of an odorant to chlorofluorocarbon refrigerants. ${ }^{12}$ This patent addresses the following five requirements of a suitable odorant: (1) the odorant inust vaporize with the refrigerant; (2) the odorant must have a noticeable odor at low conrentrations; (3) the odorant must be compatible with the refrigerant and must be nonreactive; (4) the odorant must dissipate in a reasonable time period after the leak is stopped; and (5) the odorant must not be excessively toxic.

The Saccavino and Vanek patent concludes that a refrigerant composition consisting of $<2 \%$ by weight of 3 -methylcyclohexanone or methyl isobutyl ketone would satisfy the requirements. Although $2 \%$ at first may not seem like a large amount, it would add up to nearly $300,000 \mathrm{lb}$ if applied to the combined R-114 inventories at PGDP and PORTS.

The addition of trace anounts of mercaptans to dangerous odorless gases allows early warning in case of a leak. ${ }^{13}$ The human sense of smell (olfactory sense) is capable of detecting propyl or butyl mercaptan at conculurations in air as low as $1.0 \mathrm{ppb} ;{ }^{14}$ in comparison, the TIF 5000 is capable of detecting concentrations of Freon ${ }^{\text {TM }}$ at 3 ppm. However, the mercaptan would be diluted in R-114 by peihaps as much as one part per thousand as it leaks from the vessel, and it would rapidly dilute in the air thereafter. This fact suggests that one could not hope to smell a leak of mercaptan several feet from the vessel with the same sensitivity as that of most of the available leak detection instruments applied at the leak site. Better estimates of the leakage rates detected through use of odorants would require plume calculations, which would have to be adjusted to account for the ambient air currents near the cooling systems.

\section{ORGANIC VAPOR ANAL'YZERS (FLAME IONIZATION)}

Organic vapor analyzers (OVA) are capable of detecting organic vapors in air from concentrations of $<1$ to 10,000 ppm. (The ability to detect a cuncentration of R:114 of $1 \mathrm{ppm}$ translates to a leak detection capability of $1 / 4$ ounce per year.) These instruments will respond to all organic vapors that can be ionized in a flame. Carbon monoxide will not be indicated because it burns to stable carbon dioxide. Some organic compounds do not ionize in a flame as well as others and consequently give a reduced response or no response to the OVA. $^{15}$ Experience at PGDP indicates OVA responds well to R-114.

The basic operating concept, as described in the Foxboro Company vendor literature, includes the steps listed below.

1. A smai diaphragm pump pulls the sample air with the entrained organic vapor through the test probe.

2. The air-organic vapor mixture is mixed with hydrogen gas, which fuels a small torch located between electrode sensors. 
3. The organic vapor is ionized in the flame, allowing a current to flow between the electrndes. The magnitude of the current is proportional to the amount and type of organics present. (Most instruments are calibrated on a methane basis, but can be used for other compounds and calibrated in equivalent units.).

4. An electronic signal processor amplifies and translates the generated signal and registers the output on the display as a concentration in suitable units (usually $\mathrm{ppm}$ ).

The Foxboro Company manufactures three different models of OVAs, designated OVA$88,-108$, and -128 . The last two models have the capability of incorporating a gas chromatographic column to allow the flame ionization sensor to also serve as a chromatograph sensor for separation and identification of individual compounds in an organic vapor mixture. The OVA- 88 and OVA-108 have log-scale indicator gages that cover the concentration range of $1-100,000$ and $1-10,000 \mathrm{ppm}$, respectively. The OVA-128 has three linear scale concentration ranges: 0-10, 0-100, and 0-1000 ppm. The Environmental Protection Agency (EPA) publishes protocol for estimating leaks of volatile organic compounds, and the Foxboro OVA was one of the instruments used in the protocols. ${ }^{15}$ The OVA-128 electron es are battery powered. The hydrogen cylinder is sufficient for about 8 hours of operation. The unit weighs about $12 \mathrm{lb}$. it has been used previously at PGDP for CFC leak detection and was found to be a sensitive instrument. However, it required considerable maintenance due to hydrogen leaks and was not near ly as convenient to carry as the TIF 5000 halogen leak detector.

\section{PRESSURE DECAY}

The pressure $(P)$, volume $(V)$, and absolute temperature $(T)$ of an ideal gas are related by the ideal gas equation:

$$
P V=n R T,
$$

where $R$ is the ideal gas conistant, and $n$ is the number of moles of gas a tained in the vessel. The leakage of gas from a vessel can be modeled by altering equation (1) to:

$$
L=\frac{M V}{R T}\left(\frac{\Delta P}{\Delta t}\right)
$$

where $L$ is the mass per unit time leaking from the vessel, $\Delta P / \Delta t$ is the ratio of the pressure change to the time interval required for the pressure change, and $M$ is the molecular weight of the gas. The second equation assumes that the temperature and volume remain constant during the pressure change. The second equation serves as a basis for estimating the overall leak rate from a pressurized vessel by the pressure decay leak test method; it cuuld also be used to measure leakage into an evacuated vessel (rate of rise leak test method).

The pressure in the cascade coolant system is roughly 100 psia for both the leak tests with air that are performed following leak repa:- at PORTS and during operation with R-114 in the system. The ideal gas equation is not strictly applicable at this range of pressure, but still 
can aid in the calculation of useful approximations. (Air can be expected to conform to the ideal gas law much more closely than can R-114.)

There are approximately 590 coolant systems (size 0 and larger) at PORTS and PGDP, and a goal of the R-114 loss reduction program is to reduce annual R-114 losses to $325,000 \mathrm{lb} /$ year for all systems. Such losses of R-114 seem high but amount to average losses of only $0.0629 \mathrm{lb} / \mathrm{h}$ of $\mathrm{R}-114$ in coolant systems with volumes as large as $800 \mathrm{ft}^{3}$. Such leakage rates illustrate the difficulty of trying to verify leaks in a reasonable time by observing $R-114$ coolant system inventories.

R-114 is not considered a very good gas with which to perform pressure decay tests, because it is too easily compressed to a liquid phase and because high molecular weight gases have lower diffusion rates than do lower molecular weight ones. Therefore, air is usually used for pressure decay tests. A means of relating air leakage to R-114 leakage can be developed as follows assuming isentropic flow of compressible gases: ${ }^{16}$

$$
A=\frac{L}{P \sqrt{\frac{M K g_{c}}{R T}\left(\frac{2}{K+1}\right)^{\left[\frac{(K+1)}{(K-1)}\right]}}},
$$

where

$A=$ area of leak $\left(\mathrm{ft}^{2}\right)$,

$L=$ mass leak rate $\left(\mathrm{lb}_{\mathrm{m}} / \mathrm{s}\right)$,

$P=$ pressure (psia),

$K=$ ratio of the heat capacity of the gas at constant pressure to the heat capacity at constant volume $(\mathrm{Cp} / \mathrm{Cv})$,

$g_{c}=$ gravitation constant $\left(32.17 \mathrm{lb}_{\mathrm{m}} \mathrm{ft} / \mathrm{bb}_{\mathrm{f}} \mathrm{s}^{2}\right)$,

$R=$ ideal gas constant $\left(10.73 \mathrm{psia} \cdot \mathrm{ft}^{3} / \mathrm{b}_{\text {mole }} \cdot{ }^{\circ} \mathrm{R}\right)$,

$T=$ absolite temperature $\left({ }^{\circ} \mathrm{R}\right)$,

$M=$ molecular weight of the gas.

The area of the leak will be the same whether air or R-114 is leaking from the coolant sys .em; therefore, the following equation can be written with the $a$ subscript referring to air, and the $r$ subscript referring to R-114. The constants $g_{c}$ and $R$ have been eliminated from both sides of the equation.

$$
\frac{L_{a}}{P_{a} \sqrt{\frac{M_{a} K_{a}}{T_{a}}\left(\frac{2}{K_{a}+1}\right)^{\left[\frac{\left(K_{a}+1\right)}{\left(K_{a}-1\right)}\right]}}}=\frac{L_{r}}{P_{r} \sqrt{\frac{M_{r} K_{r}}{T_{r}}\left(\frac{2}{K_{r}+1}\right)^{\left[\frac{\left(K_{r}+1\right)}{\left(K_{r}-1\right)}\right]}}} .
$$

Now equation (4) can be used to calculate the mass leak rate of air $(L a)$ at 100 psia and $100^{\circ} \mathrm{F}\left(560^{\circ} \mathrm{R}\right)$ that would result from a coolant system if an $\mathrm{R}-114$ leak of $0.063 \mathrm{lb} / \mathrm{hr}$ at 96 psia and $150^{\circ} \mathrm{F}\left(610^{\circ} \mathrm{R}\right)$ occurs in the same coolant system. The value of $K_{r}$ is 1.14 and of $K_{a}$ is 1.4. Calculations after making the necessary substitutions in equation (4) show a 
leakage rate of air of $0.030 \mathrm{lb} / \mathrm{h}$, which is about $47 \%$ of the leakage rate using $\mathrm{R}-114$ under the stated conditions.

Now equation (2) can be used to calculate the value of the air pressure change per hour by inserting the values $M=28.8, V=800 \mathrm{ft}^{3}, R=10.73 \mathrm{psia} \cdot \mathrm{ft}^{3} / \mathrm{lbmole} \cdot{ }^{\circ} \mathrm{R}, T=560^{\circ} \mathrm{R}$, and $L=0.030 \mathrm{ib} / \mathrm{h}$ and solving for $\Delta P / \Delta t$. The result is $0.0078 \mathrm{psi} / \mathrm{h}$, which is quite small.

Equation (1) can be used as a basis for calculation of the change in pressure that would result from a change of one degree rankine (fahrenheit) if no leakage of gas occurs.

$$
\left(\frac{\delta P}{\delta T}\right)_{n, v}=\frac{P}{T} \text {. }
$$

Substituting the values $100 \mathrm{psia}$ and $560^{\circ} \mathrm{R}\left(100^{\circ} \mathrm{F}\right)$ for the pressure and temperature gives the value of $0.18 \mathrm{psi} /{ }^{\circ} \mathrm{R}$, which is a pressure change twenty-three times the leakage rate per hour of air previously calculated. This means that a temperature decrease of about $0.1^{\circ} \mathrm{F}$ with no gas leakage would cause the pressure to drop about two times as much as would one hour of gas leakage at the rate of $0.030 \mathrm{lb} / \mathrm{h}$ at constant temperature. This exercise illustrates that the pressure decay method will not be practical in our application if temperature effects prove prohibitive. D. W. Langenberg is presently studying the pressure decay method in detail and has developed computer programs to assist in calculating numerous pressure decay scenarios. ${ }^{17}$

For the most sensitive pressure decay testing, a differential pressure gage is used with one leg connected to a leak-tight reference volume and the other connected to the test volume. ${ }^{18}$ Ideally the reference volume would be subject to the same temperature effects as the test volume, but such equality would be difficult to accomplish in the cascade coolant systems due to their size and configuration.

Volumetrics, Inc., manufactures several models of microprocessor-controlled pressure decay equipment. These systems can monitor pressure changes as low as $0.012 \mathrm{psi} / \mathrm{h}$ with temperature resolution of $0.001^{\circ} \mathrm{F}$. The microprocessor automatically compensates the pressure decay reading for temperature changes. Numerous temperature monitors are attached to the test vessels to provide a more accurate temperature reading.

\section{SOLID-STATE ELECTROLYTIC-CELL GAS SENSORS}

Gas detectors that employ solid-state electrolytic-cell sensors (solid-state sensors) are of fairly recent origin. The solid-state sensor was first patented in 1972. The operating principle is based on the ability of certain metal oxides from the transitional group elements of the periodic table to act as electrolytic-cells in the presence of specific gases. Two platinum alloy wires are encapsulated in the metal oxide suri that the wires are not in electrical contact with one another except via the metal oxide. Ore of the wires acts as both a heater and an anode, the other wire as a cathode. If only air is present, then the electrical conductance of the metal oxide is virtually zero, but if a specific gas is present, the gas molesules rapidly absorb into the metal oxide and increase the conductance in proportion to the amount of gas present. The sensors can be formulated to respond to only certain gases. ${ }^{19}$ 
Solid-state sensors are frequently employed to monitor toxic or combustible gas leaks. International Sensor Technology (IST) manufactures several systems for different applications. Their Model AG512 computerized monitoring system continually monitors as many as 511 individual sensing points and provides a printed record. IST also manufactures simpler models, including a small, hand-held battery-powered unit, which could be used as a sniffer-type instrument similar to the TIF 5000 although it is much more expensive $(\$ 1,375$ versus $\$ 120)$.

The solid-state sersor has reasonable calibration stability and zero. (The instrument reading returns to zero as the gas concentration returns to zero.) IST recommends calibration at a decreasing time interval ( 1 month, 3 months, then only once every 6 months). The sensors are capable of detecting leaks over a range of concentrations beginning as low as $0.8 \mathrm{lb} / y e a r$. The indicating gage on the front of the instrument is usually graduated in ppm. Halogen leak detectors are normally used rather than solid-state sensors for detecting Freon ${ }^{\mathrm{m}}$ leaks, since the halogen detectors are more sensitive; however, the increased calibration stability of the solid-state sensor offers an advantage over the halogen detectors.

\section{THERMAL CONDUCTIVITY LEAK DETECTORS}

The more expensive models of thermal conductivity leak detectors use two heated filaments that are cooled by two separate air streams-one from an intake of ambient air and the other from air drawn though the leak detecting probe. Both filaments act as electrically resistive elements in a bridge circuit. If a gas that has a thermal conductivity significantly different than air is present at the leak detecting probe, then the difference in cooling effects will cause an imbalance in the bridge circuit and give a measurement of the amount of gas being drawn though the probe. The American Society for Metals reports that these instruments can detect leaks as low as $10^{-4} \mathrm{std} \mathrm{cc} / \mathrm{s} .{ }^{1}$

Since the detector compares an ambient air stream to the air strearn entrained at the probe, the effects of any contaminants in the ambient air near the detecting probe are balanced out. The detector sensitivity and zero remain stable with use. The heated elements opera : at only $300^{\circ} \mathrm{C}$ compared to the almost $900^{\circ} \mathrm{C}$ required by the heated anode halogen detector. ${ }^{1}$ Uson Corporation manufactures a unit called the Model 510B Leak Detector, which costs $\$ 11,410$ and claims a sensitivity of only $10^{-3} \mathrm{std} \mathrm{cc} / \mathrm{s}(0.5 \mathrm{lb} /$ year of R-114). Matheson Gas Products manufactures the Model 8065 Leak Hunter, which costs $\$ 1,750$ and claims a sensitivity to Freon ${ }^{\mathrm{m}}-12$ leaks of $1.2 \times 10^{-5} \mathrm{std} \mathrm{cc} / \mathrm{s}$. The Matheson unit does not draw two gas streams or make a continuous comparison of the ambient air to the probe sample air. Instead, the instrument is zeroed in the ambient air before attempting leak detection. This feature makes the Matheson unit simpler in construction than the Uson unit.

\section{ULTRASONIC LEAK DETECTORS}

The human ear is sensitive to vibrations (sound waves) in air at frequencies below about $20 \mathrm{KHz}$, but cannot detect frequencies above that level. The frequencies of air vibrations above the human hearing level are called ultrasonic frequencies. An ultrasonic detector is an electronic instrument capable of detecting the presence and relative magnitude of ultrasonic vibrations. A sonic spectrum analyzer is an instrument capable of indicating the frequencies of these vibrations. 
An ultrasonic leak detector is a particular application of an ultrasonic detector in which the instrument is usually designed to filter out all air vibrations below or above the $30-50 \mathrm{KHz}$ range, because gases escaping from leaks under pressure generate frequencies within this range. Also, many of the vibrations outside this range are noise signals commonly caused by operating machinery and other sounds frequently found in an industrial surrounding. ${ }^{1}$

Since ultrasonic waves are of higher frequency than audible waves, their travel can be thought of as similar to that of streams of particles. That is, ultrasonic waves are much easier to block with a solid boundary than are audible waves. They have little tendency to bend around corners, but they readily reflect off flat objects.' If an electronic ultrasonic sound generator is sealed in a pipe with a small hole, ultrasonic waves will be detected only within a narrow area along a line originating from the generator and passing out the hole. Ultrasonic generators are usually about the size of a cigarette box and are frequently used to detect leakage paths in large vessels where pressurization is not practical. ${ }^{1}$ Sometimes they are used in itind leaks in automobiles by placing the ultrasonic generator inside the vehicle and surve ving the exterior with an ultrasonic leak detector. In cases in which a vessel is already pressurized, there is no increased benefit to placing an ultrasonic generator in the vessel.

The sensitivity of ultrasonic leak detectors is about $0.01 \mathrm{std} \mathrm{cc} / \mathrm{s}(5.3 \mathrm{lb} /$ year of R-114), which is considerably less than that of the halogen leak detectors, but the ultrasonic detectors provide a nearly instantaneous indication of leaks of sufficient size. ${ }^{20}$ They can also detect leaks at a distance. During a preliminary investigation of an ultrasonic leak detector at a coolant system in the K-33 building on the K-25 site, a R-114 leak was detected from six feet away. The ultrasonic signal rapidly decreased beyond six feet. Reportedly the detection distance can be increased by use of a parabolic reflector. ${ }^{1}$ Ultrasonic detectors are battery powered, lightweigitt, and compact, although they are not as handy as the TIF 5000 halogen detector. Blackmar reports that ultrasonic leak detectors are used successfully in locations at the Nalco Chemical Company where motors, process flows, and general plant operation create high-noise levels, which might appear to be unfavorable to the use of the detectors. Blackmar found the ultrasonic detector faster to use than bubbling solutions, and the ultrasonic detector allowed approximate determination of leak size based on the magnitude of the ultrasonic signal. ${ }^{21}$ Blackmar's report is encouraging concerning use of an ultrasonic leak detector in an operating cascade, but an actual evaluation is necessary to determine if background ultrasonic noise is prohibitive.

The ASTM provides the following desired specifications for an ultrasonic leak detector and accessories.

- The complete kit should include the instrument, a probe, a rubber probe extension, and earphones.

- The instrument should detect acoustic energy along the frequency range of $30-50 \mathrm{KHz}$ and provide an audible signal that can be heard over a speaker or earphones or both.

- The instrument meter should have a pointer deflection of at least $60^{\circ}$ minimum, and the meter indication should be graduated in decibels $(\mathrm{dB})$.

- The loudspeaker should be controlled by an on/off switch. 
- The audible response and meter signal should consist of the down-converted ultrasonic signal so that the audible and meter response are representative of the frequency and amplitude characteristics of the original ultrasonic signal.

- The instrument should be equipped with a ten-turn sensitivity control with a three-digit readout.

- The internal power supply should be regulated to allow sensitivity accuracy of $\pm 5 \%$ of the full meter scale over the full range of battery conditions. ${ }^{18}$

ASM reports that ultrasonic leak detectors can be used to detect leaks from pipes under fiberglass insulation. In one case, leaks of air of less than 2 psig pressure were located at distances of up to two feet away, even though the leaks were hidden under an inch of fiberglass insulation. The hole size was reported as 0.004 inch ID. W/ith no insulation present, an air leak was detected from two feet away whe' t the hole size was 0.0008 inch ID under 140 psig pressure.

The Hewlett Packard Company previously marketed an ultrasonic leak detector that mects the requirements of ASTM and was favorably evaluated by ASMi, ${ }^{1}$ Communications Technology has since purchased the Hewlett Packard rights and markets the unit as the Model C-4905A, Ultrasonic Leak Locator. They also offer Model C-8043A, Ultrasonic Reflector, which is a parabolic reflector that increases the sensitivity and range of the basic unit. The Model C-4905A and accessories, except for the C-8043A, cost about $\$ 1,500$. The C-8043A costs an additional $\$ 780$.

The American Gas and Chemical Company, Ltd., manufactures the Sonic 3000 ultrasonic leak detector, which also meets the requirements of ASTM and was favorably evaluated by ASM. The Sonic 3000 has an extension accessory so the detector probe may be attached to a long pole to allow for more precise leak detection in overhead pipes. The Sonic 3000 with most accessories costs about $\$ 2,100$.

UE Systems, Inc., manufactures the Ultraprobe 2000 ultrasonic leak detector of roughly pistol shape. This unit is a quality instrument that differs from most nther detectors in its ability to continuously vary the receiver's ultrasonic frequency range from $20 \mathrm{KHz}$ to 100 $\mathrm{KHz}$. Such variation could be an advantage in an operating cascade environment if ultrasonic background noise proves a problem. (The ability to vary the receiver frequency may allow background noise frequencies to be avoided.) The Uitraprobe 2000 unit with accessories costs about $\$ 3,800$. There are numerous additional ultrasonic detectors on the market, which vary widely in cost and have different features. The quality of some is probably equal to that of those already mentioned.

Several companies market acoustic emission leak monitoring systems that detect leaks by monitoring the vessel walls for frequencies that may be characteristic of the leaks. The monitors are placed at numerous locations along the vessel or piping. The monitored frequencies may or may not be in the ultrasonic range. The Physical Acoustics Corporation manufactures a Model 5120 acoustic emission leak monitor, which they claim detects leaks to the same sensitivities as ultrasonic leak detectors. This unit employs $A$ and $B$ probes such that $B$ is placed to detect structure-borne noise (vibrations in the vessel walls or pipe), and $A$ is attached to the potential leak site where it monitors any leakage signals as well as 
background noise signals. The higher frequency leak vibrations are not carried very far by the metal, allowing the signals at probe $A$ to be subtraced from the signals at probe $\mathrm{B}$, thereby climinating the background noise. The resulting signal is displayed on a meter and indicated audibly over earphones. NDT International, Inc., and Earl Ruble and Associates, Inc., also market acoustic emission leak monitoring systems.

\section{MISCELLANEOUS METHODS}

Additional technologies conceivably could be used for leak detection, but do not seem as practical as the methods already described and will be mentioned only briefly. Infrared absorption is based on the principle that gases absorb radiation of a certain wavelength characteristic to the specific gas, and the selective absorption provides a possible means of identifying the gas. The laser imaging concept described earlier is a special application of this principle. The more common application is to laboratory equipment to assist in chemical analysis.

Gas chromatography is based on the principle that different gases can be separated from one another and identified in very small concentrations due to the different rates at which the gases absorb and desurb from specially prepared chromatographic columns. Gas chromatography provides a very accurate means for chemical analysis in a laboratory environment, but no references could be found for its use in leak detection except as used with the OVAs described earlier. The use of a gas chromatograph with the OVA is unnecessary for detection of R-114 leaks, since the gas chromatographic column in the OVF is used for the separation of gases from a mixed organic gas stream rather than for the detection of pure gases. The gas chromatographs used in most laboratories are superior instruments, but most are too large for practical leak detection use, and the advantage of superior sensitivity is probably offset by the increased difficulty of using the instruments.

Photoionization instruments operate in a manner similar to the OVA instrument, except that the OVA uses a hydrogen flame to ionize the gas while a photoionization instrument uses ultraviolet light. According to EPA emission estimate protocols, photoionization instruments are especially useful for certain organic vapors such as formaldehyde that do not give an adequate response to the flame ionization instruments. ${ }^{15}$

The use of krypton-85 as a radioactive tracer provides for very sensitive leak detection, but the method is complex to use, and the use of a radioactive element poses obvious problems. This method is used for specialized requirements and is generally applicable only to leak testing of small devices. ${ }^{1}$

Smoke tracers are useful to detect leaks of fairly laige size. A smoke bomb is ignited inside the test vessel, and the resulting smoke pressurizes the vessel slightly and escapes from leak sites. The smoke is usually brightly colored to increase visibility. ${ }^{1}$ 


\section{LEAK QUANTIFICATION}

\section{METHODS ALLOWING ROUGH ESTIMATES OF LEAK RATES}

The ability 1 , estimate leak rates is an important point to be considered when establishing priorities for repair of leaks. The majority of the technologies described in this report have the ability to estimate leak rates to at least a limited extent. Table 1 lists each of the technologies described in this report and indicates if the method can be used to quantify leaks. (The tabie also summarizes other information.) If the leaks are small, bubbling solutions can indicate approximate leak-rates if the bubbles are counted and rough estimates of their volume are made while time is noted with a stop watch. The colorimetric methods also allow approximate leak-rate determination by noting the rate at which the coloration at the leak site grows. ASM gives the following formula for determining leak rate based on the concentration and pressure of ammonia and the time required to form a spot $1 \mathrm{~mm}$ in diameter:

Leak Rate $(\mathrm{atm} c c / s)=2.534 /\left[\left(15 p^{2}-3241\right)\left(c^{2 / 3}\right)(t)\right]$

where

$p=$ pressure of ammonia in psia

$c=$ concentration of ammonia in percent

$t=$ time in seconds to form a $1 \mathrm{~mm}$ diameter spot. ${ }^{1}$

The dye tracer method can be related roughly to leak rate since the amount of dye escaping the system per unit time can be noted. Mass spectrometers could offer some indication of leak size based on the measured helium concentration. The DIAL system of laser imaging could allow for approximate leak-rate determination since the difference in magnitude between the two reflected laser beams is proportional to the amount of gas present. $^{8}$

\section{LEAK QUANTIFICATION BY THE PRESSURE DECAY METHOD}

The pressure decay method would allow almost a direct reading of leakage rate for the entire coolant system, since calculations can be performed to convert air leakage rates to R-114 leakage rates as described earlier. The practicality of the pressure decay (or rateof-rise) method for leak quantification has yet to be demonstrated, though.

\section{LEAK QUANTIFICATION WITH AN ULTRASONIC LEAK DETECTOR}

Since the signal indicator on an ultrasonic leak detector can be adjusted for different magnitudes of ultrasonic signals, and since the signal magnitude can be related to leak rate, the ultrasonic leak detector provides a method for estimating leak rates if the leak is within the instrument's detection range (greater than $0.01 \mathrm{std} \mathrm{cc/s}$ or $5.3 \mathrm{lb} /$ year of R-114). The ultrasonic leak detector must be calibrated before it can be used for leak rate measurements. 
Table 1. Comparison of the leak detection methods

\begin{tabular}{|c|c|c|c|c|}
\hline Method & $\begin{array}{c}\text { Sensitivity } \\
\text { R-114 } \\
\text { (lb/year) } \\
\end{array}$ & $\begin{array}{c}\text { Battery } \\
\text { powered }\end{array}$ & $\begin{array}{l}\text { Quantifies } \\
\text { leakage? }\end{array}$ & $\begin{array}{c}\text { Cost per } \\
\text { instrument } \\
\text { (dollars) }\end{array}$ \\
\hline Bubbling solution & 0.01 & & $C^{c}$ & \\
\hline Zolorimetric & $5 \times 10^{-5 a}$ & & $C^{c}$ & \\
\hline Dye & 0.01 & & $C^{c}$ & \\
\hline \multicolumn{5}{|l|}{ Halogen detectors } \\
\hline - Heated anode & $5 \times 10^{-5 a}$ & No & Yes & 2,750 \\
\hline - Corona discharge & $0.03^{a}$ & Yes & No & 120 \\
\hline - Halide torch & 0.5 & & No & $<100$ \\
\hline Laser imaging & 88 & No & $\mathrm{C}^{c}$ & 60,000 \\
\hline Mass spectrometers & $5 \times 10^{-7 b}$ & No & $C^{c}$ & $15,000^{a}$ \\
\hline Odorants & Unknown & & No & \\
\hline Organic vapor analyzer & 0.1 & Yes & Yes & 6,500 \\
\hline Pressure decay & Unknown & No & Yes & $12,000^{a}$ \\
\hline Solid-state sensors & 0.8 & Yes & $\mathrm{C}^{c}$ & $1,400^{a}$ \\
\hline Thermal conductivity & 0.5 & Yes & $\mathrm{C}^{c}$ & $11,400^{a}$ \\
\hline Ultrasonic & 5.3 & Yes & Yes & $2,500^{\mathrm{a}}$ \\
\hline
\end{tabular}

${ }^{a}$ Considerable range can be expected in minimum detectable leakage rate (or cost).

${ }^{b}$ Helium is the tracer gas for the mass spectrometer, but the leak rate shown is the approximate equivalent rate for R-114.

These methods can conditionally be used to quantify leakage rates.

Note: The above sensitivity is the estimated minimum leakage rate detectable of R-114 ( $1 \mathrm{std} \mathrm{cc} / \mathrm{s}$ equals $531 \mathrm{lb} /$ year of R-114). 
ASTM recommends the following procedure for calibrating the instrument.

1. Obtain a leak standard that will supply a steady present flow rate of $1.1 \mathrm{std} \mathrm{cc} / \mathrm{s} \pm 5 \%$. (The American Gas and Chemical Company markets leak standards for this purpose.)

2. Locate the detector probe $10.0 \mathrm{~m} \pm 0.1 \mathrm{~m}$ from the calibrated leak standard and make certain the detector probe and leak source are oriented along a straight line facing each other.

3. Ensure that the instrument is on and that the batteries are fully charged, then adjust the instrument's sensitivity control to obtain a meter reading of $50 \%$ of full scale.

4. Place a sound-absorbing barrier in front of the detector probe to block the signal and confirm that the meter reading falls to zero. ${ }^{20}$

The ASTM states that the instrument should be calibrated according to the above procedure prior to each use, and it should be recalibrated at 4-h intervals. Once the instrument is calibrated, it can be used to estimate leakage rate according to the following formula:

$$
\text { Leakage Rate }(\text { std } c c / s)=0.03 \times \text { Detection Distance }(f t)^{20}
$$

The minimum instrument sensitivity of $0.01 \mathrm{std} \mathrm{cc} / \mathrm{s}$ should be kept in mind when using the above formula. (The 1986 edition of the ASTM Standard E1002-86 falsely reports the 0.03 in the above formula as 0.3.) Background noise could interfere greatly with the accuracy of the estimated leak rate.

\section{LEAK QUANTIFICATION WITH PROBE AND PUMP DETECTORS}

The OVA, the heated anode halogen leak detector, and perhaps other instruments (e.g., solid-state sensors and thermal conductivity detectors) possibly could be used to measure the rates of individual leaks if a small sample pump is used to pull the sample gas through the instrument sensor at a known flow rate. These instruments are referred to as probe and pump detectors in this report. The OVA appears to be the instrument most applicable to the quantification of leaks in coolant systems within the cascades because it does not require an electrical outlet, is equipped with a sample pump, and is more sensitive than the solid-state sensors and thermal conductivity detectors. The Foxboro OVAs have a nominal sample flow rate of $2 \mathrm{~L} / \mathrm{min}$, but they would need to be modified by installation of an adjustable calibrated flow meter in the sample flow line. The Foxboro OVAs indicate concentration in ppm. They are usually calibrated on a methane basis but can be recalibrated to other organic vapors, or the meter reading can be converted to concentrations of other organic vapors by use of a suitable multiplier. The Foxboro representative stated that the instrument response to methane is nearly the same as for R-114. (If an instrument calibrated for methane is used to detect $\mathrm{R}-114$, the meter reading should be multiplied by 1.10 .) 
If all the $\mathrm{R}-114$ that leaks is entrained at the probe, the $\mathrm{R}-114$ concentration in ppm can be related to the leak rate as follows:

$$
\begin{gathered}
C=\left(V_{R} / V_{P}\right) \times 10^{6}, \\
V_{R}=M_{R} / p \\
M_{R}=C \times 10^{-6} \times V_{p} \times \rho \times K,
\end{gathered}
$$

where

$V_{R}=$ volumetric flow rate of leaking $\mathrm{R}-114$ vapor $(\mathrm{cc} / \mathrm{s})$,

$V_{P}=$ volumetric flow rate of pump (cc/s),

$M_{R}=$ mass flow rate of leaking $\mathrm{R}-114$ (lb/year),

$\rho=$ density of $\mathrm{R}-114$ vapor,

$K=31,536,000 \mathrm{~s} /$ year,

$C=$ concentration of $\mathrm{R}-114$ vapor (ppm).

The assumption that all leaking Freon ${ }^{\top M}$ is entrained is valid only if the leak site area is small. Leaking flanges or other irregular surfaces will require speciai methods to give valid results. The EPA has published protocols for estimating leak rates of organic vapors, which describe the equipment and techniques for several methods. They suggest using mylar plastic and duct tape to make a tent around the leaking object and connecting the OVA and a manometer to the tent. The sample pump and a flow meter are used to establish a steady, known flow rate on the tent. Small holes are cut in the tent opposite the OVA line connection to keep the tent from evacuating excessively, and the flow meter is adjusted to obtain a constant pressure of about $1 \mathrm{~atm}$ on the manometer. ${ }^{15}$

After the tent pressure and sample flow rate have been established, the concentration in $\mathrm{ppm}$ is read from the instrument meter and multiplied by 1.10 to correct for R-114 (assuming the instrument was originally calibrated on a methane basis). The flow rate is read from the flow meter, and the values are plugged into the above equation to calculate the leak rate. (See Appendix $C$ for a sample density calculation.) While this method may be effective, it is obviously time consuming and not easy to perform. Unfortunately, no better way to measure rates from individual leak sites of irregularly shaped objects has been identified.

\section{RECOMMENDATIONS}

Calibrated leak sources of different sizes should be purchased or fabricated. These leak sources should be used to investigate leak rate sensitivity and to evaluate quantification abilities for R-114 leaks using the organic vapor analyzer, ultrasonic leak detector, heated anode leak detector, corona discharge leak detector, and perhaps other instruments. The 
evaulation of the equipment with the calibrated leak sources eventually shor:ld be conducted at an operating cascade to take into account the temperature and air currents in the cascade. Monitoring different locations of operating cascades with an air flow meter may provide useful information since air currents near a leak site strongly influence the R-114 concentration.

Work on the pressure deca: (rate-of-rise) method should continue to determine if the pressure change calculations can adequately compensate for temperature effects. An ultrasonic leak detector should be evaluated in an operating cascade to determine if ultrasonic background noise is at acceptable levels.

\section{CONCLUSIONS}

The average leakage loss per coolant system, assuming a total leakage loss of 325,1000 $\mathrm{lb} /$ year, is $551.0 \mathrm{lb} /$ year. Since the TIF 5000 halogen detectors and bubbling solutions are capable of detecting leaks as small as $0.03 \mathrm{lb} /$ year, the sensitivity of these methods seems more than adequate considering that a coolant system with 18,000 leak sites each leaking 0.03 $\mathrm{lb} / y e a r$ would leak a total of only $540 \mathrm{lb} / y e$ ear. Assuming that the actual number of leak sites is smaller and the leakage rate from each site is correspondingly greater, leakage should be simpler to detect than in this example. This fact suggests that there is no point in employing instruments that are more sensitive but are also more difficult to use than the TIF 5000. The TIF 5000's main disadvantage is that it does not permit leak quantification.

Remarkably few leaks are found in TIF 5000 surveys of coolant systems. Several explanations are possible. The reported sensitivity of the TIF 5000 may be far overrated, or perhaps the probe is being moved too quickly for an accurate reading. The leakage may be occurring from relatively few leaks of large size. The leakage may be occurring in places not surveyed. Portions of the coolant systems may be basically porous, with leakage occurring at tens-of-thousands of leak sites too small to locate.

The evaluation of different equipment types with calibrated leak sources should help accurately characterize the leak size in the coolant systems. Although the ultrasonic leak detector is not one of the more sensitive instruments, it may prove to be especially useful for leak surveying and quantification, since it can be used for more rapid scanning than other instruments. Also, a rough indication of leakage size can be obtained by adjusting the sensitivity control. The OVA is perhaps the best instrument for quantifying leaks, since it is a battery-powered, sensitive instrument equipped with a sample pump and gives a concentration readout in ppm.

The pressure decay method does not identify leak site locations, but may allow estimation of the overall coolant system leakage rate if temperature effects are not excessive. The use of dye, odorant, or colorimetric methods would require the addition of chemical agents to the coolant system. The use of dyes seems more attractive than the other two methods, but possible short- and long-term effects on the refrigerant and coolant system components should be evaluated prior to implementation, as should the consequences of leakage to the process gas. 


\section{$23 / 24$}

\section{REFERENCES}

1. R. C. McMaster, ed., "Leak Testing," in Nondestructive Testing Handbook, Vol. 1, 2d ed, American Society for Metals, 1982.

2. American Society for Testing and Materials, "Standard Method of Testing for Leaks Using Bubble Emission Techniques," ASTM E 515-74, Pennsylvania, 1987.

3. American Socicty for Testing and Matcrials, "Standard Method for Ammonia Colorimetric Leak Testing," ASTM E 1066-85, Pennsylvania, 1987.

4. R. C. McMaster, ed., "Liquid Penctrant Tests," in Nondestructive Testing Handbook, Vol. 2, 2d ed, American Society for Metals, 1982.

5. E. A. Jeffers, R. P. McLeroy, and L. Sacerio, "Halogen Gas Leak Detector," U.S. patent 4,488,118, December 11, 1984.

f. W. C. Worthington, "Using Refrigerant Gas For Leak Detection," Quality, 28(11), 40-41 (November 1989).

7. American Socicty for Testing and Materials, "Standard Practice for Testing for Leaks Using the Halogen Leak Detector (Alkali Ion Diode)," ASTM E 427-71, Pennsylvania, 1987. 1989).

8. A. Sobel, "Louating Leaks with Lasers," Chemical Processing, 52(9), $40-44$ (August

9. American Society for Testing and Materials, "Standard Guide for Selection of a Leak Testing Method," ASTM E 432-71, Pennsylvania, 1987.

10. American Socicty for Testing and Materials, "Standard Methods of Testing for Leaks Using the Mass Spectrometer Leak Detector or Residual Gas Analyzer in the Tracer Probe Mode," ASTM E 498-73, Pennsylvania, 1987.

11. American Society for Testing and Materials, "Standard Methods of Testing for Leaks Using the Mass Spectrometer Leak Detector in the Detector Probe Mode," ASTM E 499-73, Pennsylvania, 1987.

12. J. F. Saccavino and E. A. Vanck, "Halocarbon and Azcotrope Refrigerant Compositions Containing Offensive Warning Component.," U.S. patent 4,294,716, October 13, 1981.

13. McGraw-Hill Encyclopedia of Science and Technology, 5th ed., Vol. 8, "Mercaptan," McGraw-Hill Book Company, New York, 1982.

14. National Aeronautics and Space Administration: Leakage Testing Handbook, Liquid Propulsion Section, Jet Propulsion Laboratory, National Acronautics and Space Administration, Pasadena, California, Contract NAS 7-396, General Electric Research and Development Center, Schenectady, New York, July 1969.

15. U.S. Environmental Protection Agency, "Protocols for Generating Unit-Specific Emission Estimates for Equipment Leaks of VOC and VHAP," Emission Standards Division, Office of Air Quality Planning and Standards, Research Triangle Park, North Carolina, EPA-45013-88-010 (October 1988).

16. V. L. Streeter, "Compressible Flow," pp. 302-305 in Fluid Mechanics, 4th ed., McGraw-Hill Book Company, New York, 1966.

17. D. W. Langenberg, Martin Marietta Energy Systems, Inc., Oak Ridge, Tennessec, personal communication to E. B. Munday, Martin Marietta Energy Systems, Inc., September 14, 1990.

18. David Morris, "Leak Detection in Quality Control," Quality, 28(5), 50-52 (May 1989).

19. T. H. McKerlie, "Gas Detectors for Toxic and Combustible Vapors," Measurements and Control, p. 193, Issue 103 (February 1984).

20. American Society for Testing and Materials, "Standard Methods of Testing for Leaks Using Ultrasonics," ASTM E 1002-86, Pennsylvania, 1987.

21. Guy E. Blackmar, "Find Leaks Faster with Ultrasonic Leak Detectors," Hydrocarbon Processing, Vol. 52, N. 1 (January 1973). 


\section{ACKNOWLEDGMENTS}

The assistance of personnel at the Portsmouth Gaseous Diffusion Plant and Paducah Gaseous Diffusion Plant is appreciated. J. E. Arrowood of the K-25 Site Applied Technology Library conducted the literature search of the computer data bases. His assistance is especially appreciated. 
A-1

Appendix A

ALPHABETICAL LISTING OF VENDORS 
Appendix A

\section{ALPHABETICAL LISTING OF VENDORS}

1. Airserco Manufacturing Co., Inc.

P.O. Box 1415

Dayton, $\mathrm{OH} 45401$

513-461-1754

George E. Scott

2. Alcatel

40 Pond Park Road

$617-749-8710$

Hingham, MA 02024

3. American Gas and Chemical Company, Lid. 220 Pegasus Avenue

Northvale, NJ 07647

$201-767-7300$

4. Ametek Thermox Instruments Division 150 Freeport Road

$412-828-9040$

Pittsburgh, PA 15238

5. Ansonics, Inc. (formerly Techsonics)

P.O. Box 910

$503-742-7475$

Halfway, OR 97834

6. Biddle Instruments

510 Township Line Road

Blue Bell, PA 19422

215-646-9200

800-424-3353

7. Central States Cunsulting Co.

109 Lynn Drive

$616-962-3383$

Battle Creek, MI 49017

8. Clark Technical Produces

1112 Kevin Road

Knoxville, TN 37923

615-691-7425

David Wells

9. Communication Technology Corporation

(Dallas Office)

4000 McEwen North

Dallas, TX 75244

(Atlanta Office)

5250 Fulton Industrial Boulevard

404-691-6400

Allanta, GA 30336 
10. Cooper Tools Division

$919-362-7510$

Lufkin Road, P.O. Box 728

Apcx, NC 27502

11. CPS Products, Inc.

$305-687-4121$

4125 East 10th Court

Hialeah, FL 33013

12. Dylon Industries, Inc.

216-234-1600

120 First Avenue

Berea, OH 44017

13. Earl Ruble and Associates, Inc.

218-723-1637

424 East 1st Strcet, Suite 1

Duluth, MN 55805

14. Edwards High Vacuum, Inc.

$508-658-5410$

One Edwards Park

301 Ballardvale Street

Wilmington, MA 01887

15. Electronics for Industry, Inc.

$305-233-1640$

14380 SW 139th Court

Miami, FL 33186

16. Foxboro Company

$508-378-5634$

Environmental Monitoring Operations

P.O. Box 500, 600 North Bedford Street

East Bridgewater, MA 02333

17. Gas Technologies

$516-374-1154$

55: Green Place

Woodmere, NY 11598

18. Highside Chemicals, Inc.

$601-896-9220$

P.O. Box 3748

800-359-5599

Gulfport, MS 39505

19. International Sensor Technology

$714-863-9999$

17771 Fitch Street

Irvine, CA 92714

20. ITI Industrial

$617-272-7233$

109 Terrace Hall Avenue

Burlington, MA 01803 
21. Kernco Instruments Co., Inc.

915-852-3375

420 Kenazo Avenue

800-325-3875, Ext. 11

El Paso, TX 79927

$312-826-1700$

250 North Washtenaw Avenue

Chicago, IL 60612

23. Laser Imaging Systems

P.O. Box 1626

$813-639-3533$

Punta Gorda, FL 33951

24. Leybold Inficon, Inc.

315-434-1100

6500 Fly Road

East Syracuse, NY 13057-9714

Jerry Wander

25. Lumidor Safety Products

$305-625-6511$

5364 NW 167th Street

Miami, FL 33014

26. Mark Telephone Products, Inc.

408-727-8815

5122 Calle del Sol

Santa Clara, CA 95054

27. Material Control, Inc.

708-892-4274

719 Morton Avenue

Aurora, IL 60506

28. Matheson Gas Products

404-961-7891

6874 South Main Street

Morrow, GA 30260

29. Murray Corporation

Tile Factory Road

214-729-0151

Palcstine, TX 75801

30. NDT Interational, Inc.

711 Creek Road

215-793-1700

West Chester, PA 19382

31. Nuclear Consulating Services, Inc.

614-846-5710

P.O. Box 29151

800-992-5192

Columbus, $\mathrm{OH} 43229$

32. OTC Power Team

Division of SPX Corporation

$507-455-7100$

2121 West Bridge Street

Owatonna, MN 55060 
33. Physical Acoustics Corporation

$609-896-2255$

P.O. Boy 3135

Princetor, NJ 08540

34. Racon, Inc.

$316-524 \cdots 3245$

P.O. Box 198

6040 South Ridge Road

Wichita, KS 67201

35. Scientific-Pittsburg

(Cincinnati Office)

P.O. Box 39495

Cincinnati, OH 45239

(Pittsburg Orfice)

$412-921-7700$

130 Wabash Avenue

Pittsburg, PA 15220

36. Spectronics Corporation

$516-333-4840$ 956 Brush Hollow Road

$513-522-6040$

P.O. Box 483

Westbury, NY 11590

37. SPERRY (AW) Instruments, Inc.

$516-231-7050$

245 Marcus Boulevard

800-546-5398

Hauppauge, NY 11788

38. SPM Instrument, Inc.

P.O. Box 89

359 North Main Street

Marlborough, CT 06447

39. Tecan Remote

404-242-0977

3000 Northwoods Parkway, Suite 185

Norcross, GA 30071

40. TIF Instruments, Inc.

305.757-8811

9101 NW 7th Avenue

800-327-5060

Miami, FL 33150

41. UE Systems

914-592-1220

12 West Main Street

800-223-1325

Elmsford, NY 10523

42. Uson Corporation

$713-460-1700$

5215 Hollister

Houston, TX 77040 
43. Vacuum Instrument Corporation 2099 North Avenue Ronkonkoma, NY 11779

44. Volumetrics 3025 Buena Vista Road Paso Robles, CA 93447

805-239-0110

45. Winton Froducts Company, Inc. P.O. Box 36332

704-399-5151 Charlotte, NC 28236

46. Yokogawa Corporation of American 2 Dart Road Shenandoah, GA 30265 
B-1

Appendix B

LISTING OF VENDORS ACCORDING TO TECHNOLOGY 


\section{Appendix B}

\section{LISTING OF VENDORS ACCORDING TO TECHNOLOGY}

\section{Bubbling Solutions}

- American Gas and Chemical Comparyy, Lid.

- Dylon Industries, Inc.

- Highside Chemicals, Inc.

- LA-CO Industries, Inc.

- Winton Products Company, Inc.

Colorimetric;

- American Gas and Chemical Company, Inc.

Dyes

- American Gas and Chemical Company, Ltd.

- Highside Chemical, Inc.

- Racon, Inc.

- Spectronics Corporation

\section{Halogen Leak Detectors}

- Heated Anode

- Airserco (markets the General Electric leak detector)

- Central States Consulting Company (markets the General Electric leak detector)

- Leybold Infilon, Inc.

- Nuclear Consulting Services, Inc.

- Corona Discharge

- CPS Products, Inc.

- Kernco Instruments Co., Inc.

- Material Control, Inic.

- Murray Corporation

- Sperry (AW) Instruments

- TIF Instruments, Inc.

- Halide Torch

- Cooper Tools Division

\section{Laser Imaging}

- Laser Imaging Systems

- Tecan Remote

Mass Spectrometers

- Alcatel Vacuum Products

- Ametek Thermox Instruments Division

- Edwards High Vacuum, Inc. 
- Leybold Inficon, Inc. (LH Leybold)

- Scientific-Pittsburgh

- Vacuum Instrument Corporation

\section{Organic Vapor Analyzer}

- Foxboro Company

\section{Pressure Decay}

- Volumetrics, Inc.

\section{Solid-State Sensors}

- International Sensory Technology

- Scientific-Pittsburgh

\section{Thermal Conductivity}

- Matheson Gas Products

- Uson Corporation

\section{Ultrasonic Leak Detectors}

- Acoustic Emission Technology Corporation

- Ansonics, Inc. (formerly Techsonics)

- Biddle Instruments

- Communications Technology Corporation

- Earl Ruble and Associates, Inc.

- Electronics for Industry, Inc.

- Kernco Instruments Company, Inc.

- Lumidor Safety Products

- Mark Telephone Products, Inc.

- Material Control, Inc.

- NDT International, Inc.

- OTC Power Team (SPX Corporation)

- Physical Acoustics Corporation

- SPM Instruments, Inc.

- TIF Instruments, Inc.

- UE Systems 
C-1

Appendix C

RELATING VOLUMETRIC LEAK RATES TO MASS LEAK RATES 


\section{Appendix C}

\section{RELATING VOLUM«TRIC LEAK RATFS TO MASS LEAK RATES}

The vendors of leak detection equipment most often indicate the sensitivity of their equipment or methods in terms of volumetric measures, usually in units of std ec/s. Since the $\mathrm{R}-114$ losses are commonly measured in pounds per year, a conversion factor is needed to express std cc/s in lb/year of R-114. The calculated density value of $\mathrm{R}-114$ vapor shown below can be used as an estimate for the density of the vapor as it leaks from the coolant system.

Density $(p)$ of R-114 vapor at $100^{\circ} \mathrm{F}$ and 1 atm pressure based on the ideal gas law.

$$
\begin{aligned}
& \rho=\left(\frac{n}{v}\right) \times \text { molecular weight of R-114. } \\
& \rho=(\mathrm{P} / \mathrm{RT}) \times \text { molecular weight of R-114. } \\
& \rho=\left[14.7 \mathrm{psia} /\left(304,000\left(\mathrm{psia} \cdot \mathrm{cc} / \mathrm{lb} \text { mole } \cdot{ }^{\circ} \mathrm{R}\right) \times 560^{\circ} \mathrm{R}\right)\right] \times 170.9 \mathrm{lb} / \mathrm{lb} \text { molc. } \\
& \rho=0.00000148 \mathrm{lb} / \mathrm{cc} .
\end{aligned}
$$

Convert $1 \mathrm{std} \mathrm{cc} / \mathrm{s}$ to $\mathrm{lb} /$ year.

Mass Lcak Rate $(\mathrm{lb} / \mathrm{year})=1 \mathrm{std} \mathrm{cc} / \mathrm{s} \times\left(560^{\circ} \mathrm{R} / 492^{\circ} \mathrm{R}\right) \times(0.0000148 \mathrm{lb} / \mathrm{cc})$ $\times 31,536,000 \mathrm{~s} /$ year.

Mass Leak Rate (lb/year) $=531.2 \mathrm{lb} /$ year.

Therefore, $1 \mathrm{std} \mathrm{cc} / \mathrm{s}=531.2 \mathrm{lb} /$ year of R-114.

The above calculation is more lengthy than is necessary but was done in this manner to provide a calculation of the density of $\mathrm{R}-114$ at $100^{\circ} \mathrm{F}$ and $1 \mathrm{~atm}$. 

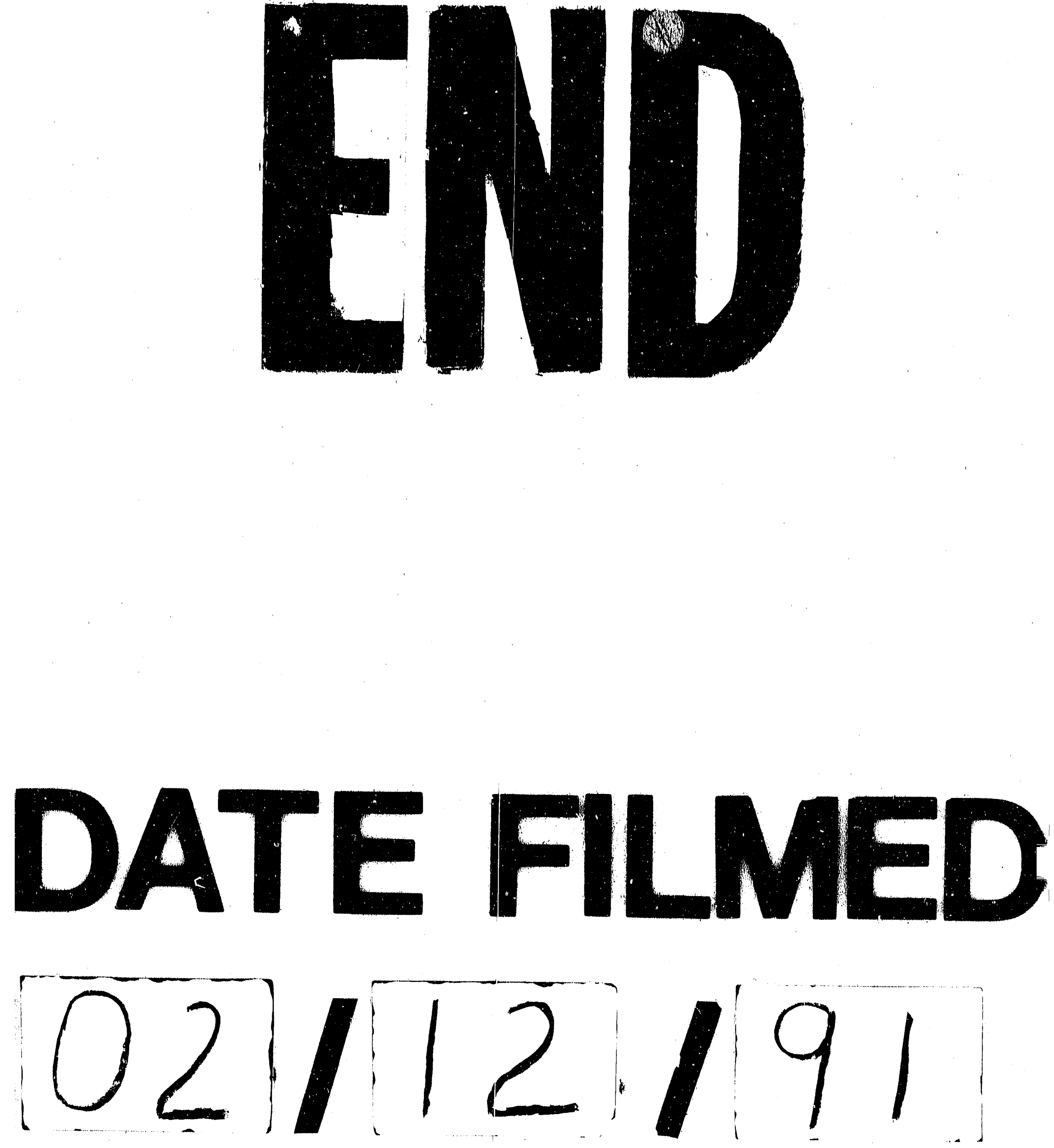
